\title{
Towards an understanding of Labrador Sea salinity drift in eddy- permitting simulations
}

\author{
Sanjay Rattan ${ }^{\mathrm{a}}$, Paul G. Myers ${ }^{\mathrm{a},{ }^{*}}$, Anne-Marie Treguier $^{\mathrm{b}}$, Sebastien Theetten ${ }^{\mathrm{b}}$, Arne Biastoch $^{\mathrm{c}}$ and \\ Claus Böning ${ }^{\mathrm{c}}$
}

\author{
${ }^{a}$ Department of Earth and Atmospheric Sciences, University of Alberta, Edmonton, Ab., Canada \\ ${ }^{b}$ Laboratoire de Physique des Oceans, Ifremer, 29280 Plouzane, France \\ ${ }^{c}$ Leibniz-Institut für Meereswissenschaften (IFM-GEOMAR), 24105 Kiel, Germany \\ *: Corresponding author: Paul G. Myers, Tel.: +1 780492 6706; fax: +1 780492 2030, email address : \\ pmyers@ualberta.ca ; A.-M. Tréguier treguier@ifremer.fr ; A. Biastoch abiastoch@ifm-geomar.de ; C. Böning \\ cboening@ifm-geomar.de
}

\begin{abstract}
:
Model drift in the Labrador Sea in eddy permitting model simulations is examined using a series of configurations based on the NEMO numerical framework. There are two phases of the drift that we can identify, beginning with an initial rapid 3-year period, associated with the adjustment of the model from its initial conditions followed by an extended model drift/adjustment that continued for at least another decade. The drift controlled the model salinity in the Labrador Sea, over-riding the variability. Thus, during this initial period, similar behavior was observed between the inter-annually forced experiments as with perpetual year forcing. The results also did not depend on whether the configuration was global, or regional North Atlantic Ocean. The inclusion of an explicit sea-ice component did not seem to have a significant impact on the interior drift. Clear cut evidence for the drift having an advective nature was shown, based on two separate currents/flow regimes. We find, as expected, the representation of freshwater in the sub-polar gyre's boundary currents important. But this study also points out another, equally important process and pathway: the input of high salinity mode water from the subtropical North Atlantic. The advective regime is dependent on the details of the model, such as the representation of the freshwater transport in the model's East Greenland Current being very sensitive to the strength of the local sea surface salinity restoring (and the underlying field that the model is being restored to).
\end{abstract}

Keywords: Numerical modelling; Labrador Sea; Model salinity drift; Boundary currents; Eddypermitting models 


\section{Introduction}

The sub-polar North Atlantic (fig. 1) is a complex region that links the Arctic Ocean and Nordic Seas to the rest of the Atlantic Ocean, while being a site of active deep water formation itself. Warm salty waters enter the region from the sub-tropical gyre carried by the North Atlantic Current, flowing east and then north before either continuing to circulate around the gyre south of Iceland (to be taken up into mode water formation - Brambilla and Talley (2008)) or continuing north into the Nordic Seas, with the exact percentage associated with either route varying with time and the North Atlantic Oscillation (Hatun et al., 2005). Cold and fresh boundary currents, the East and West Greenland Currents, plus the Labrador Current carry sea-ice and low salinity water from the Arctic as well as runoff from North America and the Greenland ice cap (Dickson et al., 2007). Deep Water formed in the Nordic Seas enter over sills in Denmark Strait and Faeroe Bank Chanel before sinking and entraining additional waters to provide the main components of North Atlantic Deep Water (Kieke and Rhein, 2006). Winter cooling leads to the formation of mode waters in the eastern parts of the gyre (Brambilla and Talley, 2008) that then circulate to the Labrador Sea where they contribute to deep convection and the formation of the Labrador Sea Water (Lazier et al., 2002), an upper, shallower component of North Atlantic Deep Water. 
On top of this base state is a tremendous amount of variability, impacting the currents (e.g. Hakkinen and Rhines, 2004) as well as the hydrography (e.g Yashayaev, 2007). Questions abound about what drives this variability, as well as how much of it is natural as compared to be anthropologically driven. As most of the oceanic observational records in this region are quite short, models will almost certainly be needed to help understand the processes acting in the region and to untangle the causes of the observed variability. Yet, before the models can be properly used to understand questions of variability, they have to be shown to be able to adequately reproduce the base state of the regional circulation and hydrography.

Although many studies have shown that high-resolution eddy permitting models can do a good job reproducing the salient features of the circulation in the region (e.g. Willebrand et al., 2001; Smith et al., 2000; Eden and Boning, 2002; Treguier et al., 2005) there are questions with respect to hydrography and water formation. Myers and Deacu (2004) performed a detailed analysis of a regional model of the sub-polar model at eddy-permitting resolution and showed significant freshwater drift occurred in the Labrador Sea. Treguier et al. (2005) examined the sub-polar gyre in 4 high resolution eddypermitting to eddy-resolving configurations (based upon the most commonly used ocean models) and also found a large drift in water mass properties in the Labrador Sea. Salinity drift in the Labrador Sea led to the formation of model Labrador Sea Water with unrealistic properties (including a too high density), negatively impacting its resulting dispersal (Boning et al., 2003). They (Treguier et al., 2005) thought the main cause for the model drift was related to the horizontal transport of salt.

In all of the studies mentioned above, the models were run in ocean-only mode and thus sea-ice was either only included in a very idealized manner, and/or not represented at all. Since sea-ice can play an important role in the transport of freshwater (Houghton and Visbeck, 2002), we wish to reexamine the issue of Labrador Sea salinity drift in models of eddy-permitting resolution that directly include a coupled sea-ice component. As well, models of these resolutions are now widely being used for global and regional ocean modelling studies, as well as for ocean reanalysis studies. Additionally, climate models are beginning to be run coupled to ocean models of these resolutions (e.g. HadGEM3). Thus, rather than focus on process studies using idealized models of variable resolution, we will directly use the models in question, at the relevent resolution (1/4 degree in this case). Additionally, by examining different configurations of the same model (basin, global, 
inter-annually forced versus perpetual year) we hope to provide a greater understanding of the processes involved. We also aim to examine in more detail the pathways associated with salt advection into the Labrador Sea.

\section{Models and Experiment Setup}

All configurations used are based on the Nucleus for European Modelling of the Ocean (NEMO)Ocean/Sea-Ice general circulation model numerical code (Madec, 2008) and use the quasi-isotropic global ORCA grid (Madec and Imbard, 1996). NEMO, including all configurations discussed in this paper, is based on the version 9.1 of the OPA primitive equation, free surface ocean general circulation model $(M a d e c, 2008)$ coupled to the sea ice model LIM2 (Fichefet and Morales Maqueda, 1997). A large suite of hind-cast and sensitivity experiments with these models have been carried out by the Drakkar Consortium DRAKKAR Group (2007). Here we focus on a small subset of these experiments that we feel best help us examine the role of model drift in the Labrador Sea.

The global hind-cast simulations used are based on the eddy permitting ORCA025 configuration (Barnier et al., 2006), described in detail in DRAKKAR Group (2007). The ORCA grid becomes finer with increasing latitudes, so the effective $\frac{1}{4}^{\circ}$ resolution is $27.75 \mathrm{~km}$ at the equator and 13.8 $\mathrm{km}$ at $60 \mathrm{~S}$ or $60 \mathrm{~N}$. It is $7 \mathrm{~km}$ in the center of the Weddell and Ross Seas and $10 \mathrm{~km}$ in the Arctic. In the vertical, there are 46 levels, finer near the surface $(6 \mathrm{~m})$, increasing with depth to $250 \mathrm{~m}$ at the bottom, with partial steps in the lowest level. The specific hind-cast experiments used here are: ORCA025-G70 (hereafter referred to as G70) carried out in Grenoble and ORCA025-KAB001 (hereafter referred to as KAB001) carried out in Kiel.

Much of the atmospheric forcing for these experiments was set up in the framework of the Co-ordinated Ocean-ice Reference Experiments (CORE) (Griffies et al., 2009), using the forcing fields developed by Large and Yeager (2009). Surface forcing for KAB001 consists of the standard CORE forcing data. Depending on the field, the resolution is 6-hourly, daily or monthly. Surface damping of sea surface salinity is weak (300 days for $10 \mathrm{~m} \mathrm{depth).}$ In addition, a full three-dimensional restoring is performed for both $\mathrm{T}$ and $\mathrm{S}$ in the polar regions with a timescale of 181 days (Biastoch et al., 2008). G70 is forced by the DRAKKAR forcing set 3 (DFS3 - Brodeau et al. (2010)). DFS3 radiation fluxes are based on CORE, while fields for the turbulent fluxes come from the ECMWF reanalysis ERA40 (instead of NCEP used in 
the standard CORE forcing). Monthly precipitation fields are based upon a blend between the uncorrected and standard CORE products, with the blend occurring between 20-30N. No three-dimensional damping is used but sea surface salinity restoring is strong $(0.1667 \mathrm{~m} /$ day $)$. Complete details on G70 forcing can be found in Molines et al. (2006). Initial conditions are based on the the World Ocean Atlas 1998 (NODC, 1998) for mean and low latitudes, with the Polar Hydrographic Climatology (Steele et al., 2001) used at high latitudes. MedAtlas was used for the Mediterranean Sea. Initial conditions for sea ice are based off a previous ORCA025 experiment using climatological CORE forcing (Molines et al., 2006). Some relevant details on these configurations for this work are described in table 1.

Additional experiments are carried out in a North-Atlantic/Nordic-Seas set-up: the $\frac{1}{4}^{\circ}$ eddy-permitting NATL4 configuration. The configuration uses the same Mercator horizontal grid, and covers the North Atlantic and Nordic Seas between $20^{\circ} \mathrm{S}$ to $80^{\circ} \mathrm{N}$. The same vertical grid as the global ORCA025 configurations G70 and KAB001 is used. Buffer zones are defined at the southern and northern boundaries as well as in the Mediterranean. General details of this configuration can be found in Le Sommer et al. (2009). Atmospheric forcing uses the CORE forcing, as in KAB001. Strong sea surface salinity restoring is used $(0.25 \mathrm{~m} /$ day $)$. A limitation of eddy permitting models is that the eddy exchanges with the interior are not well represented. Thus, to provide a rough estimate of the sensitivity of the solution to the eddy fluxes in the boundary currents, two simulations with variable (NATL4E10, hereafter referred to as PVar) and fixed (NATL4-E05, hereafter referred to as PCon) coefficient for the Gent and McWilliams (Gent and McWilliams, 1990) eddy parameterization are used. PVar includes a form of the spatially varying eddy-transfer coefficient developed by Visbeck et al. (1997) and previously used in the sub-polar North Atlantic by Deacu and Myers (2005). Further details are given in table 1.

\section{Results}

\subsection{Freshwater Content}

Freshwater content is a measure of the amount of zero salinity water that needs to be added or removed from a volume of sea water to change the salinity to a reference value.

$$
F W=\int_{V} \frac{S_{r}-S}{S_{r}} d V
$$


where $\mathrm{V}$ is the volume, $\mathrm{S}$ is the model calculated salinity and $S_{r}$ is the reference salinity. We use a reference salinity of 35.0 to be consistent with previous studies (e.g. Myers and Deacu, 2004). Defining the interior of the Labrador Sea to be the area with water depth deeper than $3000 \mathrm{~m}$ between 45-65W and 55-66N, we present timeseries of freshwater content for the entire water column for the first 14 years of integration in figure $2 \mathrm{a}$. All experiments show the decline in Labrador Sea freshwater content characteristic of eddy permitting models of this region (Treguier et al., 2005). Examining only the top $2000 \mathrm{~m}$ or top $1100 \mathrm{~m}$ (neither shown) of the water column does not change the interpretation. And since, in all cases, the initial conditions are based on observational climatologies, it shows that the model Labrador Seas are far away from reality.

The decline in freshwater is very similar in all experiments. In fact, for the first 3 years of simulations, the evolution of freshwater in the Labrador Sea is almost identical. Several interesting conclusions can be drawn from this. Firstly, the inclusion of an explicit sea-ice component does not seem to make much difference in whether such a drift occurs or not. Secondly, the behavior is similar in both the global and regional configurations, with global and regional experiments (G70-PCon and KAB001-PVar) having basically the same final freshwater content after 14 years. Thirdly, and potentially most important, the behavior is the same in the inter-annually forced experiments as with the perpetual year forcing and independent of the forcing used (e.g. ERA40 or CORE). This suggests that the Labrador Sea hydrography in the inter-annual experiments is being driven by spin-up/drift dynamics during these first 14 years, and this process is not significantly impacted by the details of the forcing variability during this period. Only after this initial spin-up phase is completed does the impact of the inter-annual forcing come into play (fig. 2b). Advection is dominant here, as the 3-D restoring using by $\mathrm{KAB} 001$ is able to provide a long term resevoir of freshwater to be exported from the Arctic.

This spin-up period also seems to be divided into two phases. The initial period, occurring over about 3 years, is probably related to mis-matches between the hydrography the model is initialized with and the circulation the model initially establishes. This should not be a surprise since most models are initialized with climatological products such as the world ocean atlas (Boyer et al., 2005), which have generally employed significant smoothing in their production and lack sharp features such as boundary currents and fronts. For example, Kulan and Myers (2009) showed that traditional 
global/basin scale climatologies of the Labrador Sea do not compare well with detailed regional products. High resolution climatological products associated with each sub-region of the ocean may be needed to deal with this issue. Although one could argue that this short initial spin-up period may be most important as it is when the model drift is initiated, we are going to focus mainly on the second phase here in this manuscript. An obvious way to extend this work would be to consider different initial conditions, since that may impact the drift as well as having implications for the initialization of decadal prediction. However, we leave this for a future study.

\subsection{Mixed Layer Depth and Labrador Sea Water}

What is the impact of this drift and the excessive depths of convection on Labrador Sea water formation? Figure 3 shows the average March mixed layer depth from year 14 in each simulation (which is 1971 in the hind-cast simulations). All experiments show monthly average maximum mixed layer depths of 2000-2500 m. Observations suggest depths of convection in the Labrador Sea vary over a large range. For example Yashayaev and Loder (2009) reported depths ranging from 700 to $1600 \mathrm{~m}$ in the 2000s. Convection was observed to reach $2300 \mathrm{~m}$ in 1989 (Haine et al., 2007). Since 1971 in the real world was associated with the great salinity anomaly (Dickson et al., 1988, e.g.) and very weak convection in the Labrador Sea, the salinification is driving excess convection in all experiments and thus hiding the real interannual variability. Excessive and unrealistic convection is observed in the Irminger Sea in all experiments other than KAB001, which has different turbulent fluxes as well as precipitation fields (table 1) although the difference between this run and the others is also related to the large scale advection and the maintenance (or lack thereof) of the deeper stratification in the different experiments. Although there is observational evidence of deep convection in the Irminger Sea, it is thought to be associated with high frequency wind events called tip-jets off Cape Farewell (e.g. Pickart et al., 2003) that are not well resolved in our model simulations. Significant differences exist in the depths and extent of convection between G70 and KAB001 (as well as the NATL4 simulations). Also note the differences in mixed layer depths in the eastern basin, which will be significant later on in this discussion.

What is the impact of this drift and the excessive depths of convection of Labrador Sea water formation? Figure 4 shows the transformation rate associated with different density classes in the interior of the Labrador Sea $(>3000$ $\mathrm{m}$ ) based upon changes in volume between successive model monthly means, 
averaged over years 10 to 14 of the integrations. In all experiments, there is a shift in the core density of Labrador Sea Water from its classically defined range of 27.74-27.8 to densities greater than 27.8. Although attempting to give an observational estimate of Labrador Sea Water formation is fraught with difficulties (Haine et al., 2007), mean long term formation is probably less than the 4-6 Sv seen in all experiments other than KAB001. For example, based upon a water mass transformation approach, NCEP air/sea fluxes and a spatially varying surface water climatology, Myers et al. (2007) estimated a long term mean formation rate of between $2.1 \pm 0.2$ and $3.9 \pm$ $0.3 \mathrm{~Sv}$ over the years 1960-99.

\subsection{Links Between LSW and Sub-Polar Salinity}

To try and understand what processes may be impacting Labrador Sea Water formation, we correlate timeseries of total transformation rate in the Labrador Sea with salinity throughout the upper water column of the subpolar gyre and Nordic Seas (fig. 5). We focus on G70 since it has the largest drift, but also present results from KAB001 to help us understand the differences between those two experiments.

As one might expect, we can see a strong correlation between salinity anomalies in the top $200 \mathrm{~m}$ in the Labrador Sea and Labrador Sea Water transformation anomalies. Both experiments also show a strong positive correlation with salinity anomalies in the top $200 \mathrm{~m}$ of the Labrador Current. There are also strong correlations with the salinity in the East Greenland Current (and also the West Greenland Current in KAB001), although interesting they are negative. Finally, at a lag of 6 months, G70 reveals correlations with the salinity, especially in the 200 to $1100 \mathrm{~m}$ depth range in the eastern basin around Reykjanes Ridge, that are absent in KAB001.

This analysis thus suggests processes that we need to look at: sources of freshwater local to the Labrador Sea like sea-ice melt and precipitation, pro-

cess in the boundary currents such as the Labrador Current and East/West Greenland Currents as well as links with the eastern basin.

\subsection{Sea-Ice}

Figure 6a shows the monthly change in sea ice volume (converted to an implied freshwater flux) for the Labrador Coast south of $66 \mathrm{~N}$, as well as the East Greenland Current and Nordic Seas, over the final year of integration for PVar (fields are similar in other experiments). With an implied annual freshwater provision of $12.8 \mathrm{mSv}$, sea ice melt might be an important source 
of freshwater in the Nordic Seas. With an annual provision of $1.3 \mathrm{mSv}$ along the Labrador Current, this term is not a major contributor to the overall freshwater budget of the Labrador Sea, and thus not a significant contributor to the observed model drift. The results are similar for KAB001 (Fig. 6a), with a net provision of $2.1 \mathrm{mSv}$ along the Labrador Current and G70 (not shown). This is not surprising since numerous studies discuss how the central Labrador Sea remains free of sea ice (e.g. Mysak et al., 1990; Schmidt and Send, 2007).

The use of a fully prognostic sea ice model is a major improvement compared with previous numerical experiments (Treguier et al., 2005), but of course the representation of sea ice has to be validated. Figure 7 shows the March averaged sea ice concentrations and sea ice edge from the final year of PVar, as well as the sea ice edge from two data products: Walsh's (Walsh, 1978) 1 degree 1970-2004 climatology and the 1971-2006 Canadian Ice Service charts. The model does a reasonably good job of simulating the ice extent in Winter and Spring. Even features like the Odden ice tongue north of Iceland are represented. There is not sufficient penetration of ice southward in the East Greenland Current, associated with a poor representation of that current and too warm sea surface temperatures. The model ice edge is too far to the north in the northern Labrador Sea, but is reasonably well simulated along the Labrador Current. The model sea ice field pulls back to the north too fast in summer and the sea ice edge is poorly simulated in summer (not shown). This can also be seen in a comparison of ice covered area between the model and the climatology (fig. 6b). This also shows a more serious underestimation of the sea-ice area along the Labrador Current in KAB001. That said, for our purpose of examining freshwater input to the Labrador Sea, the model deficiencies in sea ice should mainly effect the timing of the pulse associated with the ice melt rather than the total amount of freshwater provided. This may explain why the main provision of freshwater from ice melt is earlier in the models (fig. 6) than the observations (Schmidt and Send, 2007).

\subsection{Precipitation Minus Evaporation}

Since the model simulations include a sea surface salinity restoring term, we examine the model net upward water flux, rather than just considering the precipitation and evaporation in the forcing data set. Concentrating on the interior of the Labrador Sea (depths greater than $3000 \mathrm{~m}$ ), we find the net flux to the ocean over the final year of integration varies from $6.9 \mathrm{mSv}$ in KAB001 
to $12.1 \mathrm{mSv}$ in G70 to $13.1 \mathrm{mSv}$ in PVar to $15.9 \mathrm{mSv}$ in PCon. These numbers are smaller than observations (it has been suggested that the net precipitation is in the range of 20 to $40 \mathrm{mSv}$ from reanalysis data for the Labrador Sea (e.g. Walsh and Portis, 1999; Myers et al., 2007)). and are dominated by the sea surface restoring term. For example, in G70, the damping term provides $9.2 \mathrm{mSv}$ of the net $12.1 \mathrm{mSv}$ observed in that experiment. Therefore this term may be playing a role in the model drift, although it is noted that the least net precipitation is observed in the experiment with the smallest drift. This suggests that the surface forcing is not the main driver of the model drift and points towards an advective origin.

\subsection{Labrador Current}

The main sources of freshwater to the Labrador Current are from the Baffin Island Current through Davis Strait (Cuny et al., 2005) and Hudson Strait (Loder et al., 1998) which drains Hudson Bay. Since a significant portion of the freshwater observed outflowing from Hudson Strait may have an origin in the outflow at Davis Strait (Straneo and Saucier, 2008), we examine the model export of freshwater through Davis Strait.

To do this, we project the model fields on to the locations of the moorings used by Cuny (Cuny et al., 2005) (fig. 1). Although the different time periods make direct comparisons with a given observational section difficult, we feel that using an observational section provides us with a greater ability to assess the model's field than just using an idealized section along a set of model grid lines. For all such projections onto observational sections that we present in this paper, we use the first 14 years of integration for the inter-annual hindcast experiments since this is the period of the initial model drift. For the perpetual year runs, we use the final year (although averaging over the last 3 or 4 years does not significantly change the results - we are unable to average over the entirety of these experiments as the relevant model fields were not saved frequently enough during the first few years). All experiments have freshwater exported from Baffin Bay into the Labrador Sea, albeit at different rates (fig. 8a).

The smallest exports, much smaller than the observational estimate of $92 \pm 34 \mathrm{mSv}$ by Cuny et al. (2005), are for the two NATL4 configurations with a closed Baffin Bay with no pathway from the Arctic Ocean through the Canadian Arctic Archipelago. G70 has the largest mean freshwater export of $76 \mathrm{mSv}$, close to the observational range while KAB001 has a smaller freshwater transport of $51 \mathrm{mSv}$. Since our goal is not to examine the processes 
driving export from the Arctic in the global hind-casts but instead to consider Labrador Sea freshwater drift, we do not pursue the causes of these differences further, other than noting that each of these simulations involves different numerical choices in the Arctic. For a detailed examination of the freshwater budget of the Arctic in experiment G70, the reader is referred to Lique et al. (2009).

With respect to our main question of Labrador Sea freshwater drift, we note that the largest drift occurs in experiment G70, which has the greatest freshwater export through Davis Strait. Additionally, the freshwater export through Davis Strait in the two NATL4 experiments is almost identical (differing by less than $0.5 \mathrm{mSv}$ ) even though the drift behavior is different in the two experiments. This is consistent with Myers (2005) who suggested that freshwater exchange between the Labrador Current (based on modified freshwater outflows from Davis Strait) and the Labrador Sea north of the Grand Banks is small in eddy permitting models. The eventual fate of the freshwater exported from the Canadian Arctic Archipelago is thus still an open question for further research.

\subsection{East Greenland Current}

We project our model fields onto two observational sections used by Sutherland and Pickart (2008), one at Denmark Strait (their section 5) and one just east of Cape Farewell (their section 1 - location shown on fig 1). At Denmark Strait (fig. 9), all simulations show generally similar features, with isohalines sloping down to the west towards Greenland in the top $300 \mathrm{~m}$, a strong halocline and a thick layer of saltier water below. East Greenland Current salinities are lowest and closest to the observed in KAB001 although the isohaline slope is steeper than the observations (Sutherland and Pickart, 2008) in all cases. All experiments represent the strong deep southward flow in the middle of the channel, as well as the surface intensified northward flowing Icelandic Irminger Current, although its magnitude is much lower than observed (Sutherland and Pickart, 2008). The strong southward flow on the shelf is not well represented in any of the simulations. Looking at the southward freshwater transport in the EGC (defined as inshore of the 34.8 isohaline), (fig. 8b), shows the largest southward transport occurs in KAB001 with $69 \mathrm{mSv}$ and the smallest is G70 at $41 \mathrm{mSv}$ southwards and the other experiments in between. Sutherland and Pickart (2008) gave a total adjusted freshwater flux at the same section for 2004 of $59 \mathrm{mSv}$, referenced to 
34.8. Recomputing our freshwater transports using a reference of 34.8 (figure not shown) gives estimates between $36 \mathrm{mSv}$ in $\mathrm{G} 70$ and $61 \mathrm{mSv}$ in KAB001.

The situation changes significantly by the southern end of the East Greenland Current, near Cape Farewell (Fig. 10). The spatial extend of the freshwater core has reduced in all experiments, as has the minimum salinity. Jet speeds are low, under $0.2 \mathrm{~m} \mathrm{~s}^{-1}$, except in PVar which also has the shallowest frontal slope, consistent with the observations (Sutherland and Pickart, 2008), due to its inclusion of the GM parameterization. Transport differences between the global runs has increased (not shown) with an increase in freshwater transport in KAB001 as compared to Denmark Strait (85 mSv) while the G70 freshwater transport has decreased to $18 \mathrm{mSv}$. The seasonal cycle has also completely disappeared in G70 as well. Sutherland and Pickart (2008) found an increase in freshwater transport along the EGC in 2004, with $96 \mathrm{mSv}$ at Cape Farewell.

The decline in freshwater transport in G70 as compared to the observations, as well as KAB001, can be related to the sea surface salinity (SSS) restoring. As given in table 1, G70 has strong SSS restoring (60 days as compared to 300 days in KAB001), which is amplified under ice. The annual average of the monthly SSS restoring field is shown in figure 11a. As is common for global climatologies produced using large spatial analysis scales, there is a poor representation of narrow boundary currents such as the EGC. Thus, the fairly strong surface restoring is acting to kill the fresh low salinity core in G70 (and also in the two NATL4 simulations), pushing the surface salinities towards values in the mid-34 range. Also, G70 uses a form of the CORE precipitation whereby the freshwater flux to the ocean is reduced north of $30^{\circ}$ by 15-20\% compared to that used in KAB001. The behavior (and forcing) in PCon is very similar to G70, with a decline in freshwater transport between Denmark Strait and Cape Farewell. PVar also has a reduction in freshwater transport along the course of the EGC, but the decrease is smaller. The difference with this experiment is the presence of the spatially varying GM parameterization. The parameterization is highly active, with large kappa's (greater than $600 \mathrm{~m}^{2} \mathrm{~s}^{-1}$, in the northern Irminger Sea south of Denmark Strait and along the EGC (fig. 11b). Although the parameterization is shallowing the front between the EGC and the Irminger Sea, this reduces the potential energy available for baroclinic instability and thus reduces the number of large resolved eddies that are produced in this simulation (fig. 11c). In comparison, in PCon (fig. 11d), steep isopycnals lead to the formation of large resolved eddies in the northern Irminger Sea 
that lead to significant exchange with the interior of the Irminger Sea and thus increase the salinity of the EGC. To quantify this, we examine the transport across the $2000 \mathrm{~m}$ isobath along the EGC between Denmark Strait and Cape Farewell. To consider the resolved eddies, we decompose the fields into their mean and fluctuating components over the last year of integration and compare $\bar{u} \bar{T}$ and $u^{\prime} T^{\prime}$ for the two experiments. Here $\mathrm{u}$ is the relevant velocity component (depending on the given model cell face) and $\mathrm{T}$ is the tracer (heat or salinity), while the over bar represents a time average and ' indicates a fluctuation. The results are given in table 2 and shows significantly enhanced transport of heat and salt across the shelf break by resolved eddies into the EGC in PCon.

\subsection{West Greenland Current}

As the East Greenland Current rounds Cape Farewell, it becomes the West Greenland Current. Model fields are projected onto a 5 station section west of Cape Farewell (fig 1) than has been extensively analyzed by Myers et al. (2007, 2009) (Fig. 12). A broad and deep freshwater core is seen in KAB001, with significant inflow of $71 \mathrm{mSv}$ freshwater to the Labrador Sea (fig. 8c), with amounts consistent with a recent observational estimate (Myers et al., 2009). Little freshwater (13 mSv) is input in G70. Again, in the regional simulations, PVar has a shallower but broader and freshwater core than PCon, and thus provides a large freshwater input to the Labrador Sea. Since the West Greenland Current is the main source of freshwater to the interior of the Labrador Sea (Schmidt and Send, 2007) and most of what passes the Cape Farewell section enters the interior of the Labrador Sea (Myers et al., 2009), we see one factor associated with the previously calculated model drift. The runs with largest drift are those with smallest input of freshwater from the West Greenland Current.

\subsection{Irminger Water}

But the input of freshwater is not the only way that the West Greenland Current impacts the observed Labrador Sea salinity drift. This current is also a major source of heat and salt for re-stratification (Straneo, 2006) through the provision of Irminger Water. Figure 12 shows that the differences in salinity between the experiments are even more significant with respect to Irminger Water than for the freshwater core on the shelf. The global simulations are completely different, with a strong core of Irminger Water visible 
in G70 while only an indistinct region of slightly higher backgrounds salinity is seen offshore in KAB001. The transport of IW is given in figure $8 \mathrm{~d}$, defining IW as waters warmer than $3.5 \mathrm{C}$ and saltier than 34.88 , consistent with Myers et al. (2007). We use a reference salinity of 34.8 here rather than 35.0 to avoid issues with the lower salinities in the global runs and thus alternating signs of the transport. The seasonal cycle of this transport is the same in the different runs, but on an annual average, G70 imports an extra $20 \mathrm{mSv}$ of salt into the Labrador Sea. There is also a clear difference in the two regional experiments, both of which well represent the Irminger Water Core. In PCon, this core is saltier (reaching 35.08, which is higher than any observation), deeper and much more extensive. Here, the difference in salt transport is larger, with PCon provided an extra $15 \mathrm{mSv}$ of salt to the Labrador Sea, which is larger than the difference in freshwater input through the WGC in the two experiments. All told, this suggests that focussing on low salinity inflow to the Labrador Sea will allow one to see only part of the cause of model drift in this basin. This is an idea we will expound on more in the discussion section below.

\section{Summary and Discussion}

We have investigated model drift in the Labrador Sea in a series of eddypermitting configurations based on the NEMO numerical framework. In all simulations, large salinity drift occurred in the interior of the Labrador Sea, significantly impacting mixed layer depth, density of the resulting Labrador Sea Water, as well as formation rates. The key ideas that come out of this analysis are thus:

- The rapidity of the drift. As shown, the drift was split into two periods, beginning with an initial 3 year period, associated with the adjustment of the model from its initial conditions, that was almost identical in all simulations. Basically by the end of this initial 2 to 3 year period, all simulations had significantly diverged from the observations. This suggests that further research must be carried out to test whether different strategies of model initialisation could limit this initial drift.

- The initial drift does not depend on whether the configuration is global, or a regional North Atlantic Ocean. This demonstrates that the representation of the freshwater flux through the Canadian archipelago using 
a global model does not improve significantly the freshwater balance of the Labrador Sea over a time scale of a decade. However, as shown with the later changes in freshwater content, approaching year 2000, the presence (and representation) of the Arctic Ocean and its fluxes becomes important.

- The inclusion of an explicit sea-ice component did not seem to have a significant impact on the interior drift. Which is not to say that representing the sea-ice is not important for ocean or climatic studies, just that little of it (in solid, or in liquid form after melting) reaches the interior of the Labrador Sea.

- The forcing details during the first stage of the drift are irrelevant. The simulations we examined used different air-sea fluxes as well as significantly different sea surface salinity restoring strategies and yet the behavior in the Labrador Sea was the same in each case.

- The over-riding of the inter-annual variability during both stages of the drift. As shown, similar behavior during both drift phases was seen in both inter-annual and perpetual year experiments. Again, the forcing details are not significant in controlling the initial model drift. Thus clear cut evidence for the drift having an advective nature.

- Our study provides clear cut evidence for the drift having an advective nature related to two sources, the freshwater pathways around Greenland and the transport of warm salty water by the Irminger Current.

- The details of the advective pathways are very dependent on the details of the specific model factors and parameterization. An example of this is the critical influence of the spurious influence in the East Greenland Current due to the restoring to smoothed (and thus wrong) salinity climatologies on the shelf.

As discussed in the introduction, numerous studies (e.g. Myers and Deacu, 2004; Treguier et al., 2005) have attempted to understand the causes of model drift in the Labrador Sea. Treguier et al. (2005) suggested that the salt may be coming from the eastern part of the sub-polar gyre and the North Atlantic Current. This study confirms this result with updated models, a more in-depth analysis and a comparison of freshwater transports with the observations. Although as mentioned above, the representation of the freshwater 
pathways around Greenland is crucial to correctly simulating the hydrography and circulation within the Labrador Sea, this study very clearly points out an equally important process and pathway. Here, the input of increased amounts of high salinity mode water in the Irminger Current are shown to be as significant in producing drift in the Labrador Sea. Note that Deshayes et al. (2007), analysing the variability of a different model, also find a significant role of the Irminger sea water mass formation and its advection by the boundary current.

Our study provides another set of processes that modellers need to focus on improving in there simulations to improve their underlying model, especially with regard to the key issue of Labrador Sea Water formation. The understanding appears as a prerequisite for a realistic initialization of model simulations aiming at decadal prediction of the North Atlantic circulation system. Although a detailed examination of mode water formation and the factors affecting its salinity in high resolution eddy permitting models is beyond this study, it does point to a significant need to understand processes that will affect mode water formation and salinity. Especially since a number of recent observational studies (e.g. Myers et al., 2007; Thierry et al., 2007; Biastoch et al., 2008) suggest tremendous inter-annual and inter-decadal variability in these water masses.

We suggest that much further research is needed on the processes controlling the initial drift behavior. Some of these processes include (in no particular order of importance): details of the fractionization of the NAC, e.g., how much proceeds into the Nordic Seas, and how much recirculates in the Irminger Current; the source waters of the NAC, i.e., salinity of the subtropical gyre, input of Mediterranean Water; size, extent and variability of the sub-polar gyre; inter-gyre exchange processes; representation of the overflows from the Nordic Seas and mixing/entrainment with the other water masses of the sub-polar North Atlantic; and the impact of model initialization (including initial conditions) on these phenomena in model integrations.

Overall, our study points out to the necessity of an improvement of advective processes and especially the boundary currents of the subpolar gyre, but our focus on these currents has also exposed local deficiencies in the model surface forcing that were not apparent in previous studies at lower resolution, such as Griffies et al. (2009). We demonstrate the representation of the freshwater transport in the model's East Greenland Current seems to be very sensitive to the strength of the sea surface salinity restoring. Modellers use strong sea surface salinity restoring due to poor roepresentation 
of oceanic precipitation and evaporation, to control model drift and bring fields closer to the observations (Griffies et al., 2009). But, as shown here, if the field that is being restored too does not represent the underlying current, strong sea surface salinity restoring, may in the end, contribute to the model drift that it's use is trying to avoid. Since narrow boundary currents are often poorly represented in large-scale climatological products, it may be that strong restoring is distorting the majority of these currents, not just the East Greenland Current. High resolution regional climatologies are clearly needed, both to improve model initial conditions and to constrain their surface salinity.

\section{Acknowledgments}

This work was funded by Natural Sciences and Engineering Research Council of Canada (NSERC) and Canadian Foundation for Climate and Atmospheric Sciences (CFCAS) grants (the latter through the CLIVAR and GOAPP networks) awarded to PGM. In addition, the collaboratory interactions were supported by the Deutscher Akademischer Austausch Dienst (DAAD) Visiting Scholar Program, as well as the France-Canada Research Fund (FFCR). AMT and ST are funded through CNRS. The DRAKKAR simulations were carried out at the IDRIS computing centre (G70) and the University of Kiel (KAB001). $\mathrm{CB}$ and $\mathrm{AB}$ are funded through the NORDATLANTIK program of BMBF. We also thank two anonymous reviewers for useful comments on an earlier draft of this paper.

\section{References}

Barnier, B., et al. (2006), Impact of partial steps and momentum advection schemes in a global ocean circulation model at eddy permitting resolution, Ocean Dynamics, 56, 543-567, doi:10.1007/s10236-006-0082-1.

Biastoch, A., C. W. Boening, J. Getzlaff, J. Molines, and G. Madec (2008), Causes of interannual-decadal variability in the meridional overturning circulation of the midlatitude North Atlantic Ocean, Journal of Climate, 21, 6599-6615.

Boning, C. W., M. Rhein, J. Dengg, and C. Dorow (2003), Modelling CFC inventories and formation rates of Labrador Sea Water, Geophysical Research Letters, 30, 22-1 to 22-4. 
Boyer, T., S. Levitus, H. Garcia, R. Locarnini, C. Stephens, and J. Antonov (2005), Objective analyses of annual, seasonal, and monthly temperature and salinity for the world ocean on a 1/4degree grid, International Journal of Climatology, 25, 931-945.

Brambilla, E., and L. D. Talley (2008), Subpolar mode water in the northeastern Atlantic: 1. Averaged properties and mean circulation, Journal of Geophysical Research, 113, doi:C04025/10.1029/2006JC004062.

Brodeau, L., A. Treguier, T. Penduff, and S. Gulev (2010), An ERA40-based atmospheric forcing for global ocean circulation models, Ocean Modelling, in press.

Cuny, J., P. Rhines, and R. Kwok (2005), Davis Strait volume, freshwater and heat transport, Deep Sea Research, 52, 519-542.

Deacu, D., and P. G. Myers (2005), Effect of a variable eddy transfer coefficient in an eddy-permitting model of the Sub-Polar North Atlantic, Journal of Physical Oceanography, 35, 289-307.

Deshayes, J., C. Frankignoul, and H. Drange (2007), Formation and export of deep water in the Labrador and Irminger Seas in a GCM, DSR, 54, $510-532$.

Dickson, R., B. Rudels, S. Dye, M. Karcher, J. Meincke, and I. Yashayaev (2007), Current estimates of freshwater flux through Arctic and subarctic seas, Progress in Oceanography, 73, 210-230.

Dickson, R. R., J. Meincke, S.-A. Malmberg, and A. J. Lee (1988), 'The Great Salinity Anomaly' in the northern North Atlantic 1968-1982, Progress in Oceanography, 20, 103-151.

DRAKKAR Group (2007), Eddy-permitting Ocean Circulation Hindcasts of past decades, CLIVAR Exchanges No 42, 12, 8-10.

Eden, C., and C. Boning (2002), Sources of eddy kinetic energy in the Labrador Sea, Journal of Physical Oceanography, 32, 3346-3363.

Fichefet, T., and M. A. Morales Maqueda (1997), Sensitivity of a global sea ice model to the treatment of ice thermodynamics and dynamics, Journal of Geophysical Research, 102, 12,609-12,646. 
Gent, P. R., and J. C. McWilliams (1990), Isopycnal mixing in ocean circulation models, Journal of Physical Oceanography, 20, 150-155.

Griffies, S. M., et al. (2009), Coordinated ocean-ice reference experiments (COREs), Ocean Modelling, 26, 1-46.

Haine, T., C. Boning, P. Branch, J. Fischer, A. Funk, D. Kieke, E. Kvaleberg, and M. Rhein (2007), North Atlantic deep water transformation in the Labrador Sea, recirculation through the subpolar gyre and discharge to the subtropics, in ASOF Science Book, edited by B. Dickson, in press.

Hakkinen, S., and P. B. Rhines (2004), Decline of subpolar North Atlantic circulation during the 1990s, Science, 304, 555-559.

Hatun, H., A. B. Sando, H. Drange, B. Hansen, and H. Valdimarsson (2005), Influence of the Atlantic subpolar gyre on the thermohaline circulation, Science, 309, 1841-1844.

Houghton, R. W., and M. H. Visbeck (2002), Quasi-decadal salinity fluctuations in the Labrador Sea, Journal of Physical Oceanography, 32, 687-701.

Kieke, D., and M. Rhein (2006), Variability of the overflow water transport in the Western Subpolar North Atlantic, 1950-97, Journal of Physical Oceanography, 36, 435-456.

Kulan, N., and P. G. Myers (2009), Comparing two climatologies of the Labrador Sea: Geopotential vs. isopycnal, Atmosphere-Ocean, 47, 19-39, doi:10.3137/OC281.2009.

Large, W. G., and S. G. Yeager (2009), The global climatology of an interannually varying air-sea flux data set, Clim. Dyn., 33, 341-464, doi: 10.1007/s00382-008-0441-3.

Lazier, J., R. Hendry, A. Clarke, I. Yashayaev, and P. Rhines (2002), Convection and restratification in the labrador sea, 1990-2000, Deep Sea Research, 49, 1819-1835.

Le Sommer, J., T. Penduff, S. Theetten, G. Madec, and B. Barnier (2009), How momentum advection schemes influence current-topography interactions at eddy permitting resolution, Ocean Modelling, 29, 1-14. 
Lique, C., A. M. Treguier, M. Scheinert, and T. Penduff (2009), A modelbased study of ice and freshwater transport variabilities along both sides of Greenland, Climate Dynamics, in press.

Loder, J. W., B. Petrie, and G. Gawarkiewicz (1998), The costal ocean off northeastern North America: A large-scale view, in The Sea, Volume 11, edited by A. R. Robinson and K. H. Brink, pp. 105-133, John Wiley and Sons, Inc.

Madec, G. (2008), Nemo ocean engine, Tech. Rep. Notes de Pole de modelisation, 27, ISSN No 1288-1619, Institut Pierre-Simon Palace (IPSL).

Madec, G., and M. Imbard (1996), A global ocean mesh to overcome the north pole singularity, Climate Dynamics, 12, 381-388.

Molines, J. M., et al. (2006), Le modele DRAKKAR de la variabilite oceanique globale, 1958-2004, La Lettre de l'IDRIS, p. 11 pages.

Myers, P. G. (2005), Impact of freshwater from the Canadian Arctic Archipelago on Labrador Sea Water formation, Geophysical Research Letters, 32, L06605, doi:10.1029/2004GL022082.

Myers, P. G., and D. Deacu (2004), Labrador Sea freshwater content in a model with a partial cell topographic representation, Ocean Modelling, 6, 359-377.

Myers, P. G., N. Kulan, and M. H. Ribergaard (2007), Irminger Water variability in the West Greenland Current, Geophysical Research Letters, 34, doi:L17601/10.1029/2007GL030419.

Myers, P. G., C. Donnelly, and M. H. Ribergaard (2009), Structure and variability of the west greenland current in summer derived from 6 repeat standard sections, Progress in Oceanography, 80, 93-112, doi: 10.1017/j.pocean.2008.12.003.

Mysak, L. A., D. K. Manak, and R. F. Marsden (1990), Sea-ice anomalies in the Greenland and Labrador Seas during 1901-1984 and their relation to an interdecadal climate cycle, Climate Dynamics, 5, 111-133.

NODC (1998), World ocean atlas 1998, Tech. rep., NOAA, U.S. Department of Commernce. 
Pickart, R. S., M. A. Spall, M. H. Ribergaard, G. W. K. Moore, and R. F. Milliff (2003), Deep convection in the Irminger Sea forced by the Greenland tip jet, Nature, 424, 152-156.

Schmidt, S., and U. Send (2007), Origin and composition of seasonal Labrador Sea freshwater, Journal of Physical Oceanography, 37, 14451454 .

Smith, R. D., M. E. Maltrud, F. O. Bryan, and M. W. Hecht (2000), Numerical representation of North Atlantic Ocean at $\frac{1}{10}^{\circ}$, Journal of Physical Oceanography, 30, 1532-1561.

Steele, M., R. Morley, and W. Ermold (2001), PHC: A global ocean hydrography with a high-quality Arctic Ocean, Journal of Climate, 14, 2079-2087.

Straneo, F. (2006), Heat and freshwater transport through the central Labrador Sea, Journal of Physical Oceanography, 36, 606-628.

Straneo, F., and F. Saucier (2008), The outflow from Hudson Strait and its contribution to the Labrador Current, Deep Sea Research, 55, 926-946.

Sutherland, D., and R. Pickart (2008), The East Greenland Coastal Current: Structure, variability and forcing, Progress in Oceanography, 78.

Thierry, V., E. de Boisson, and H. Mercier (2007), Rapid changes in the properties of the Reykjanes Ridge Mode Water over 1990-2006, Deep Sea Research, submitted.

Treguier, A. M., S. Theeten, E. P. Chassignet, T. Penduff, R. Smith, L. T. J. O. Beismann, and C. Boning (2005), The North Atlantic subpolar gyre in four high-resolution models, Journal of Physical Oceanography, 35, 757774 .

Visbeck, M., J. Marshall, T. Haine, and M. Spall (1997), Specification of eddy transfer coefficients in coarse-reoslution ocean circulation models, Journal of Physical Oceanography, 27, 381-402.

Walsh, J. E. (1978), A data set on northern hemisphere sea ice extent. world data center-a for glaciology (snow and ice), glaciological data, part 1, Tech. Rep. Report GD-2. 
Walsh, J. E., and D. H. Portis (1999), Variations of precipitation and evaporation over the North Atlantic Ocean, 1958-1997, Journal of Geophysical Research, 104, 16,613-16,631.

Willebrand, J., B. Barnier, C. Boning, C. Dietrich, P. D. Killworth, C. Le Provost, Y. Jia, J. Molines, and A. L. New (2001), Circulation characteristics in three eddy-permitting models of the North Atlantic, Progress in Oceanography, 48, 123-161.

Yashayaev, I. (2007), Hydrographic changes in the Labrador Sea, 1960-2005, Progress in Oceanography, 73, 242-276.

Yashayaev, I., and J. W. Loder (2009), Enhanced production of Labrador Sea Water in 2008, Geophysical Research Letters, 36, doi: L01606,10.1029/2008GL036162. 
Table 1: Table highlighting some features of the different model simulations used in this study. CORE stands for the Coordinated Ocean-ice Reference Experiments.

$\begin{array}{lcccc} & \text { G70 } & \text { KAB001 } & \text { PVar } & \text { PCon } \\ \text { Domain } & \text { Global } & \text { Global } & \text { North Atlantic } & \text { North Atlantic } \\ \text { Integration Period } & 1958-2004 & 1958-2004 & \text { 14-yr perpetual year } & \text { 14-yr perpetual year } \\ \text { Radiation Fluxes } & \text { CORE } & \text { CORE } & \text { CORE } & \text { CORE } \\ \text { Turbulent Fluxes } & \text { ERA40 } & \text { CORE } & \text { CORE } & \text { CORE } \\ \text { Precipitation } & \text { modified CORE } & \text { CORE } & \text { CORE } & \text { CORE } \\ \text { 3-D Restoring in Polar Regions } & \text { None } & 181 \text { days } & \text { None } & \text { None } \\ \text { SSS Restoring } & 0.1666667 \mathrm{~m} / \text { day } & 0.0333 \mathrm{~m} / \text { day } & 0.25 \mathrm{~m} / \text { day } & 0.25 \mathrm{~m} / \text { day } \\ \text { GM Parameterization } & \text { No } & \text { No } & \text { variable kappa } & \text { constant kappa }\end{array}$


Table 2: Estimates of the transport of heat and salt across the $2000 \mathrm{~m}$ isobath by resolved eddies.

$$
\text { PCon PVar }
$$

Heat $u^{\prime} T^{\prime} \quad-13.3 \times 10^{12}-3.63 \times 10^{12}$

Salt $u^{\prime} S^{\prime} \quad-3.09 \times 10^{6} \quad-.84 \times 10^{6}$ 


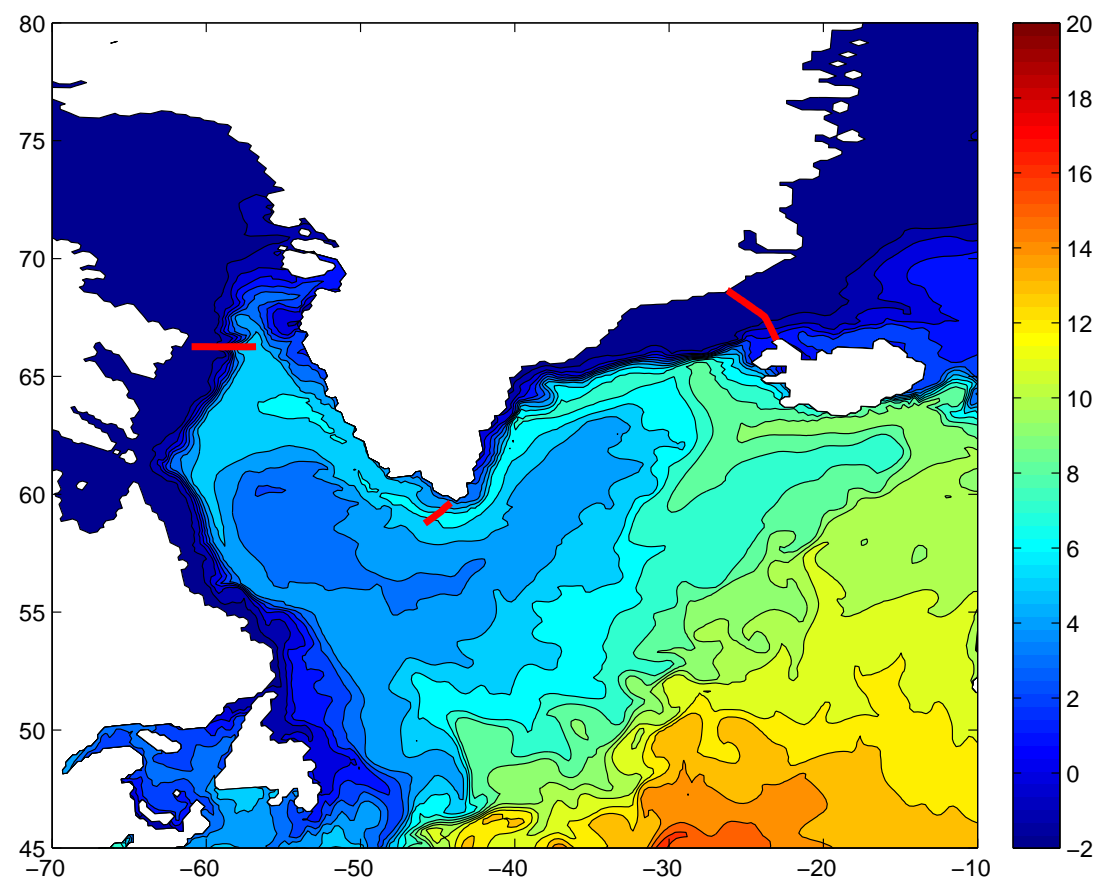

Figure 1: General map of the sub-polar gyre. The underlying field is the model sea surface temperature from January, 2004, from the KAB001 experiment. The thick red lines indicate the Davis Strait, Denmark Strait and Cape Farewell sections used to calculate model transports, as discussed in the text. 

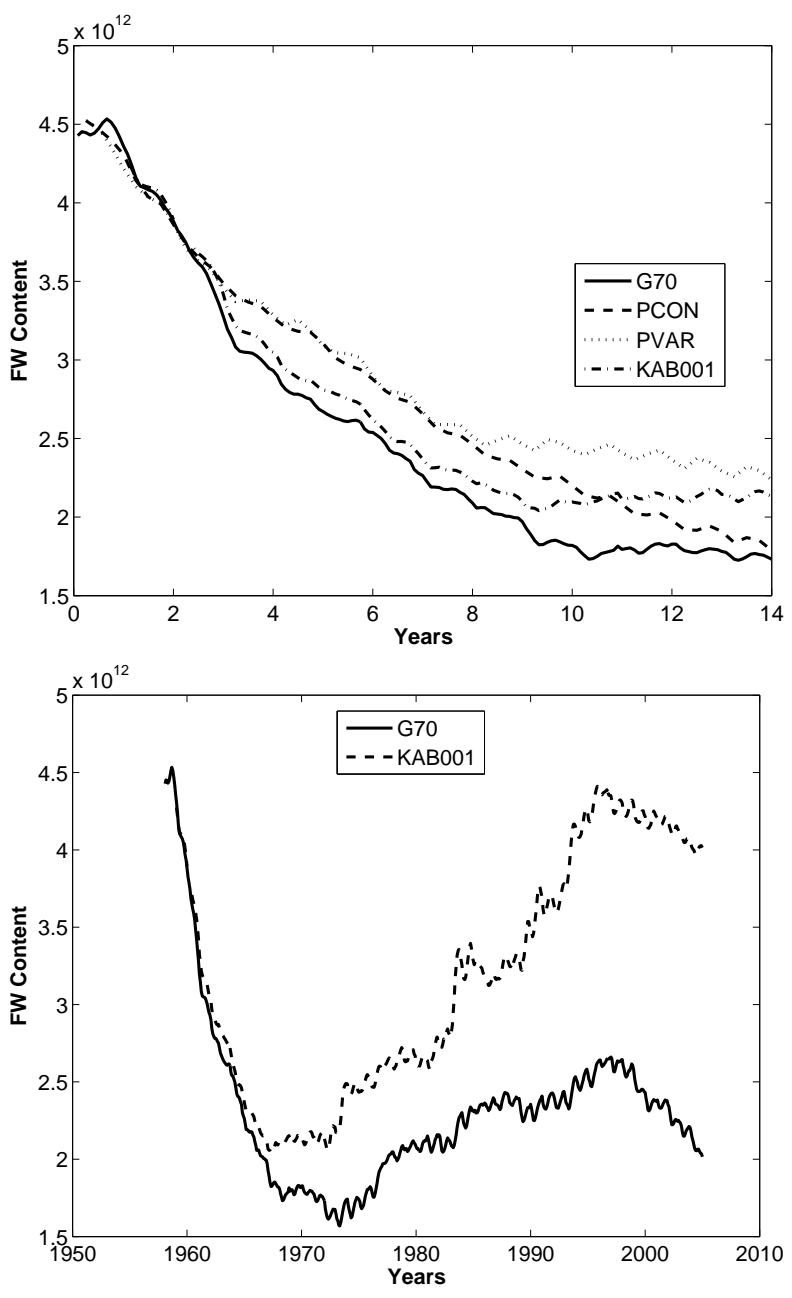

Figure 2: Drift in freshwater content in the interior of the Labrador Sea (defined as the region with depths greater than $3000 \mathrm{~m}$ between $55-66 \mathrm{~N}$ and $45-65 \mathrm{~W}$ ). The top panel focuses on the first 14 years of integration (1958-1971 for the inter-annual hindcast experiments), while the lower panel shows the time evolution through the entirety of the global hind-cast simulations. 

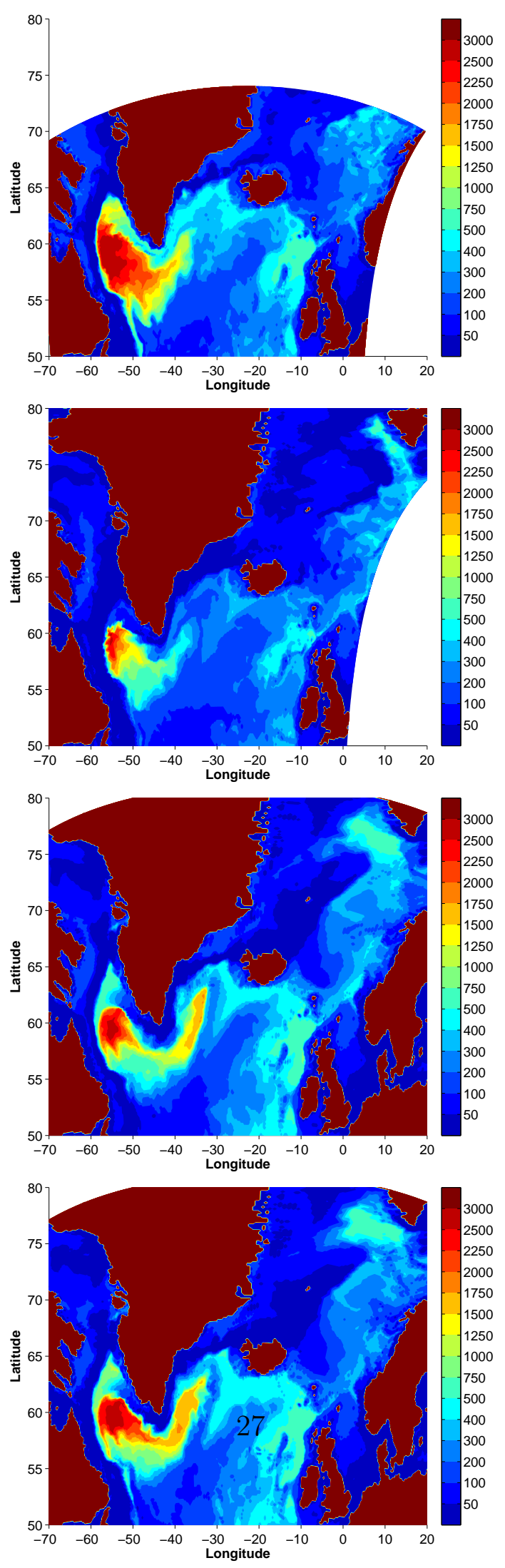

Figure 3: Average sub-polar gyre March mixed layer depths, from year 14 of each integration, for (a) G70; (b) KAB001; (c) PVar) and (d) PCon. 


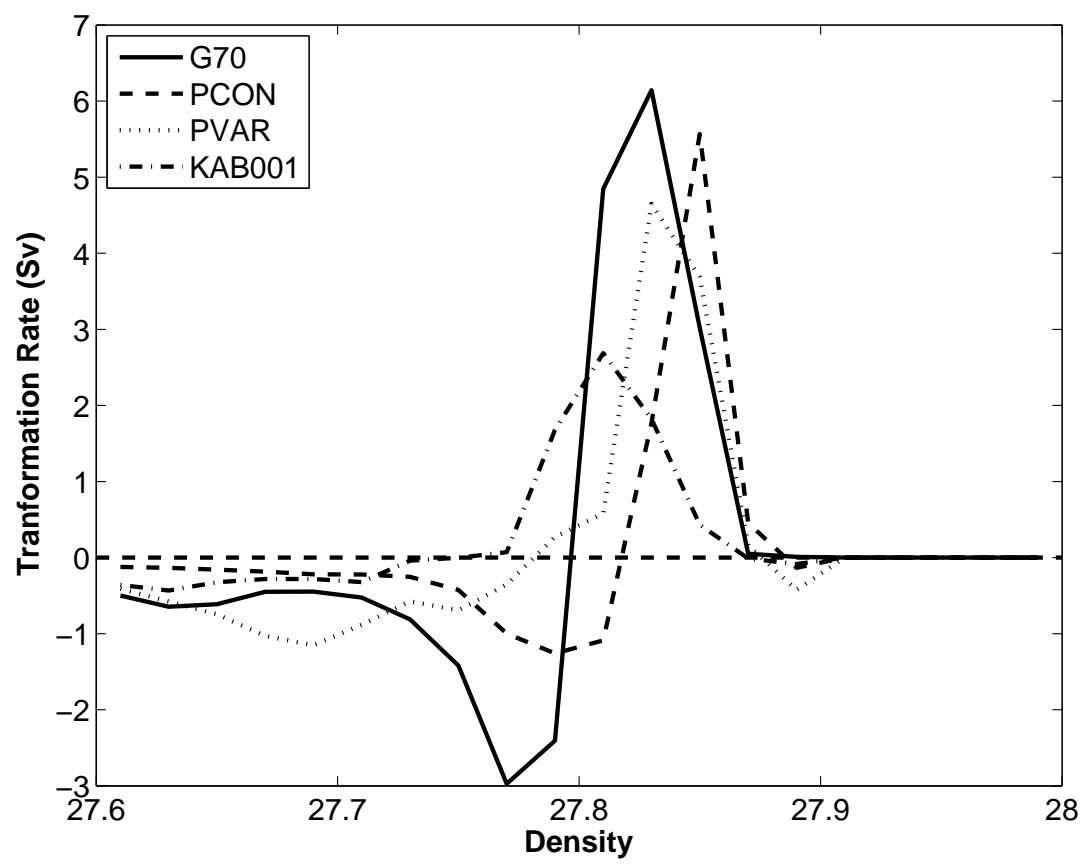

Figure 4: Formation in different density classes in the interior of the Labrador Sea (defined as the region with depths greater than $3000 \mathrm{~m}$ between $55-66 \mathrm{~N}$ and $45-65 \mathrm{~W}$ ), averaged over years 10-14 for each experiment. 

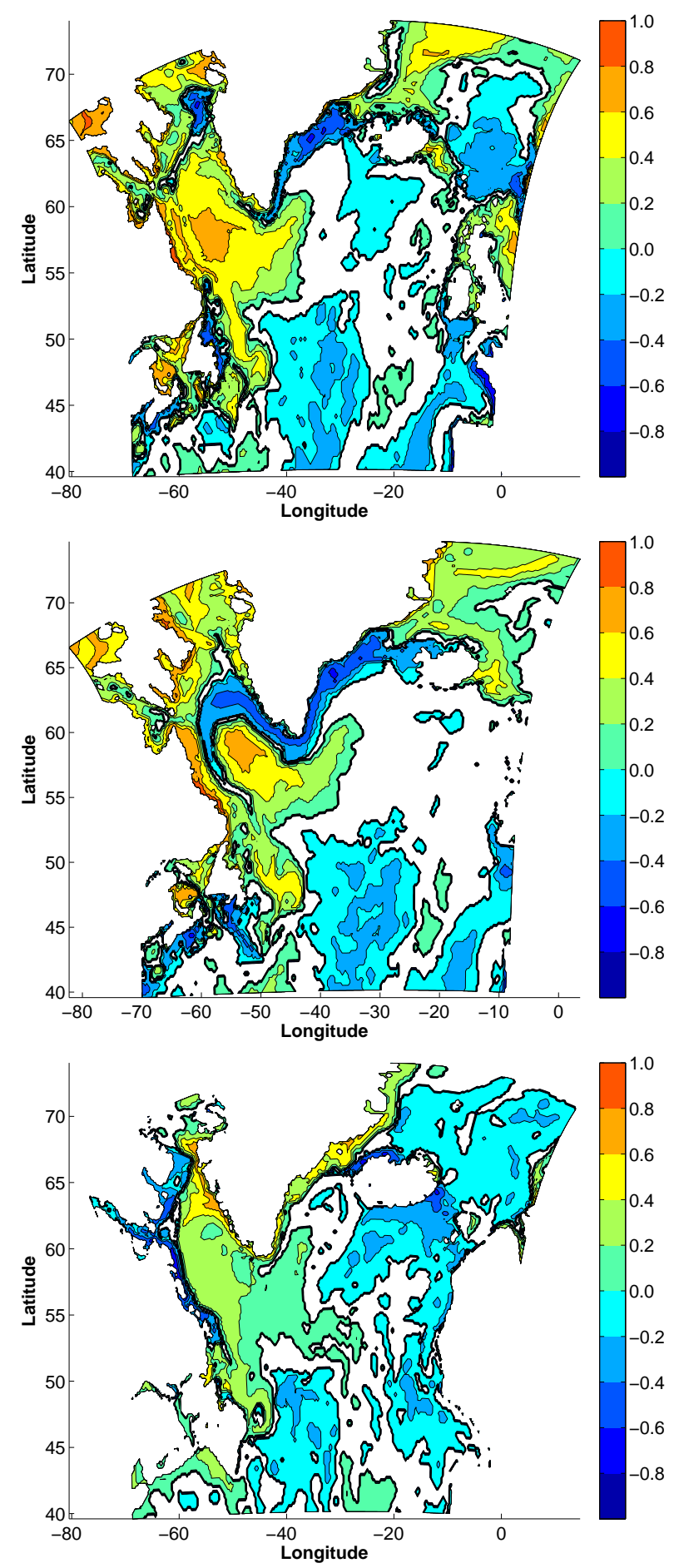

Figure 5: Correlation between total formation in the Labrador Sea (integral of fields shown in figure 4) and model salinity fields, avera@gd over the top $200 \mathrm{~m}$ at lag 0 for the first 2 panels and over 200-1100 $\mathrm{m}$ at a lag of 6 months for the last. The first and third panels are for G70 while the middle panel is for KAB001. Values of the correlation that are not significantly different from zero at the $95 \%$ level are not shaded. 

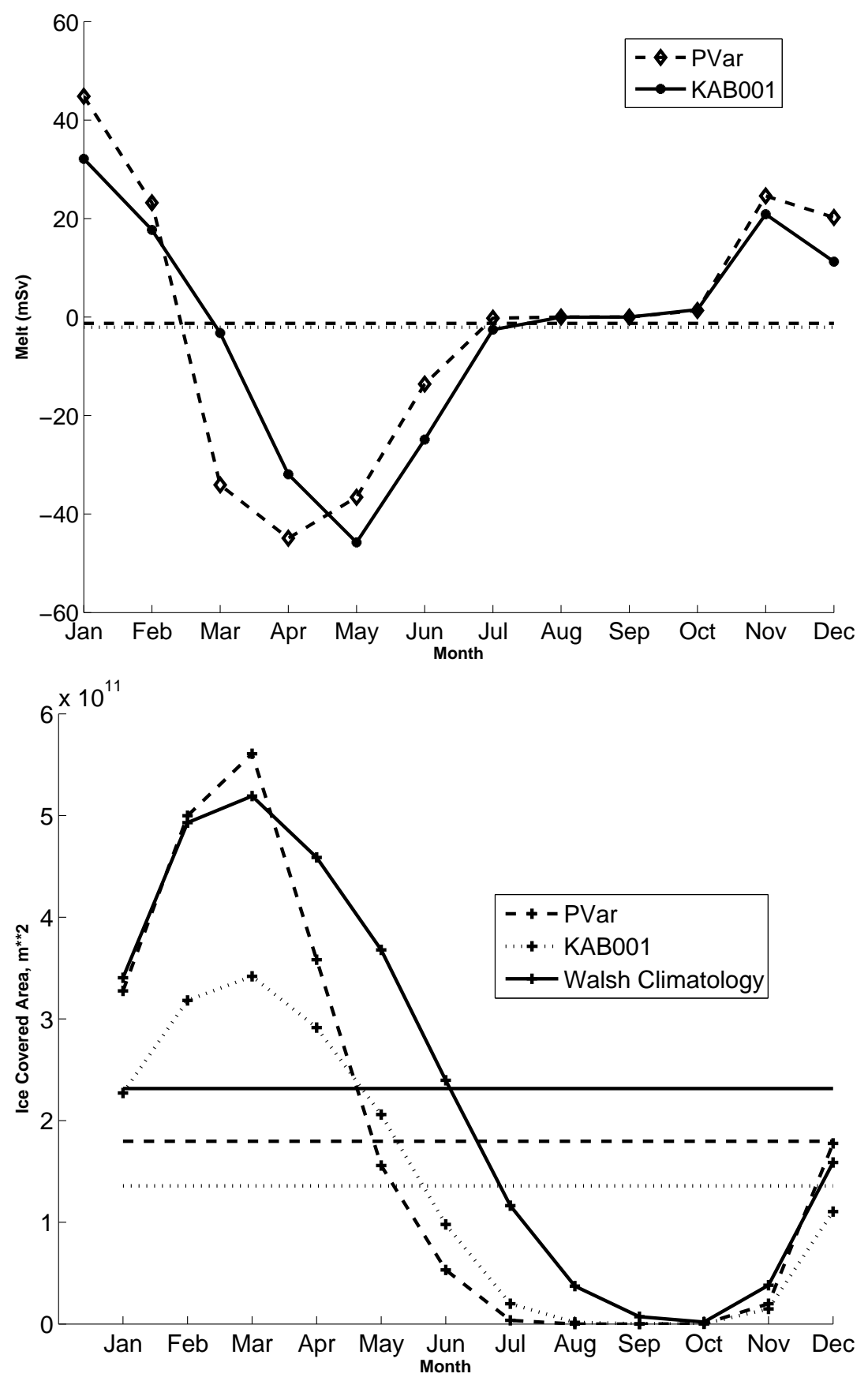

Figure 6: (top) Annual cycle of sea ice melt, converted to a net freshwater flux to the ocean, from experiments PVar and KAB001, for the Labrador Current. The dashed line is the annual average of the model melt for PVar while the dotted line is the annual average of the model melt for KAB001. (bottom) Annual cycle of ice covered area along the Labrador Coast from PVar and KAB097 compared with the Walsh (1978) 1-degree climatology. The dashed line is the annual annual average of the ice covered area along the Labrador Current from PVAR, the dashed line is for KAB001 while the solid line is for the Walsh climatology. 


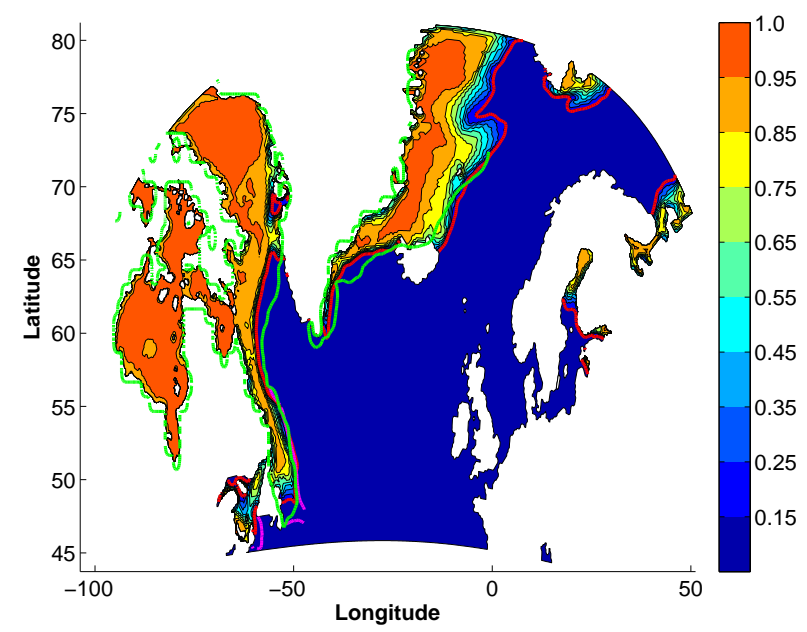

Figure 7: Sea ice concentrations fields from the last year of integration of PVar, for March. Superimposed are the climatological ice edge positions from the Walsh (1978) 1-degree climatology, in green, and from Canadian Ice Service charts, in red. 

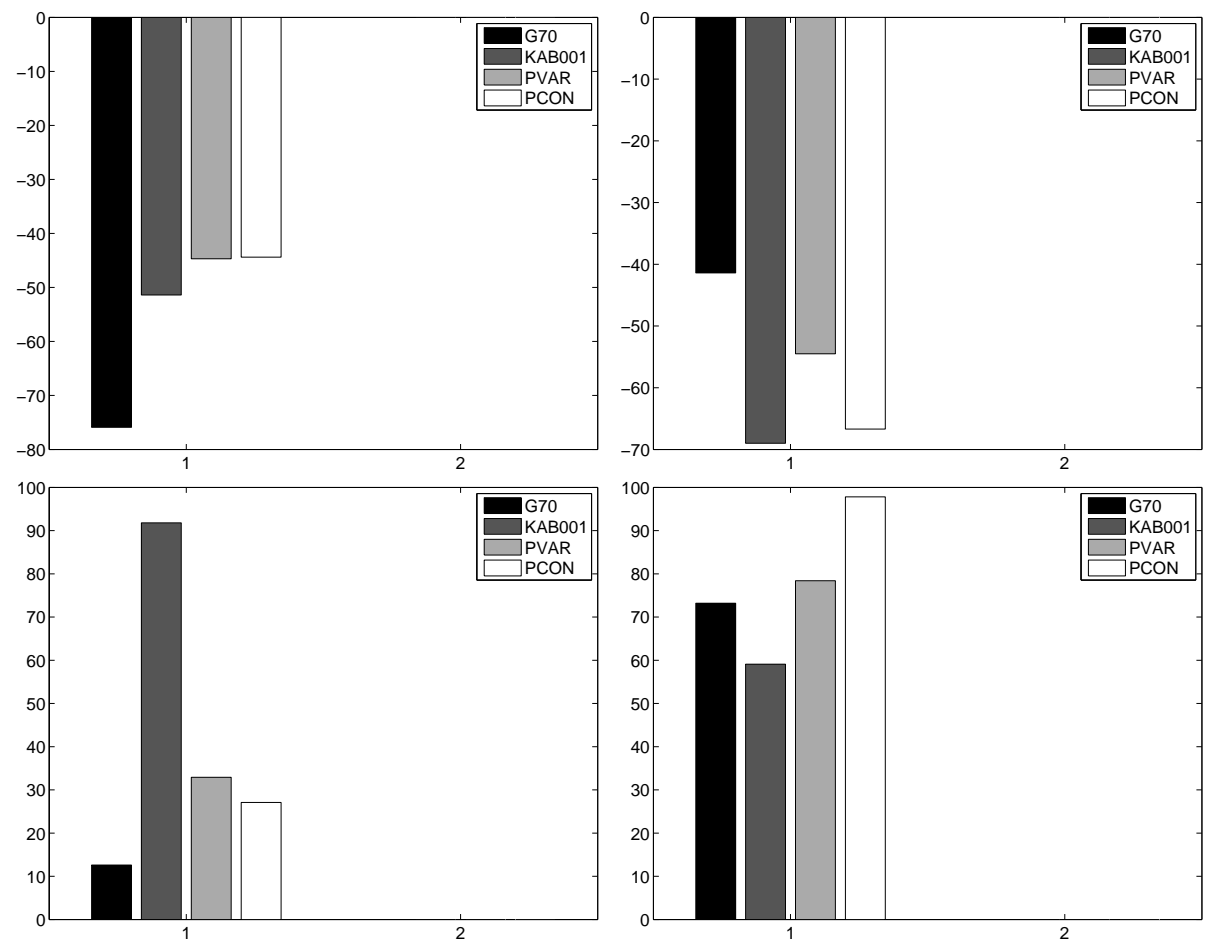

Figure 8: a) Mean freshwater transport, referenced to a salinity of 35.0 , in $\mathrm{mSv}$, for the Baffin Island Current in Davis Strait, for each experiment. The negative sign indicates that the freshwater transport is southward. b) As for a), but for East Greenland Current in Denmark Strait. c) as for a), but for the West Greenland Current just west of Cape Farewell. Note that the sign is positive for this panel since the transport is to the north here. d) Northward salt transport for the Irminger Water in the West Greenland Current just west of Cape Farewell, relative to a salinity of 34.8. The location of all sections are indicated on fig 1 - note that panels $\mathrm{c}$ and $\mathrm{d}$ are based on the same observational section. In all cases, the values for G70 and KAB001 are averaged over the first 14 years of integrations, while those for PVAR and PCON are means over the final year of integration. 

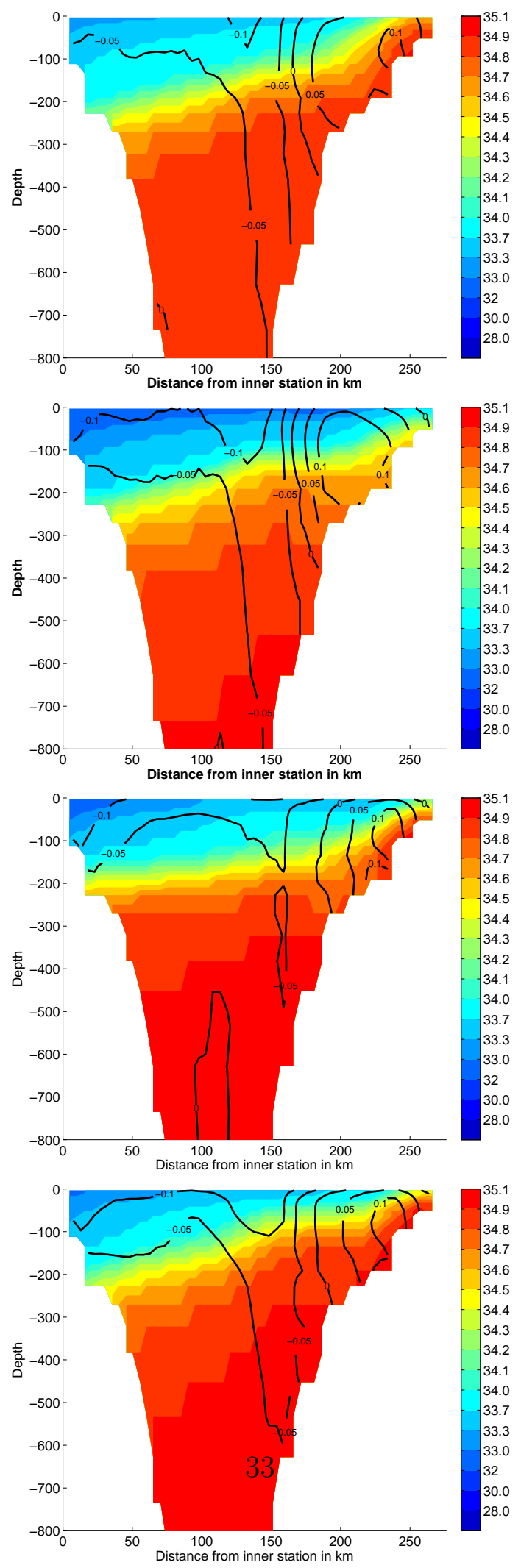

Figure 9: Model salinities and velocities projected onto section 5 of Sutherland and Pickart (2008) at Denmark Strait, for (a) G70; (b) KAB001; (c) PVar and (d) PCon. For the two global simulations, the fields are based over the first 14 years of integration, while the fields from the regional North Atlantic simulations are based on the last year of integration. The solid lines are contours of model velocities perpendicular to the section. 

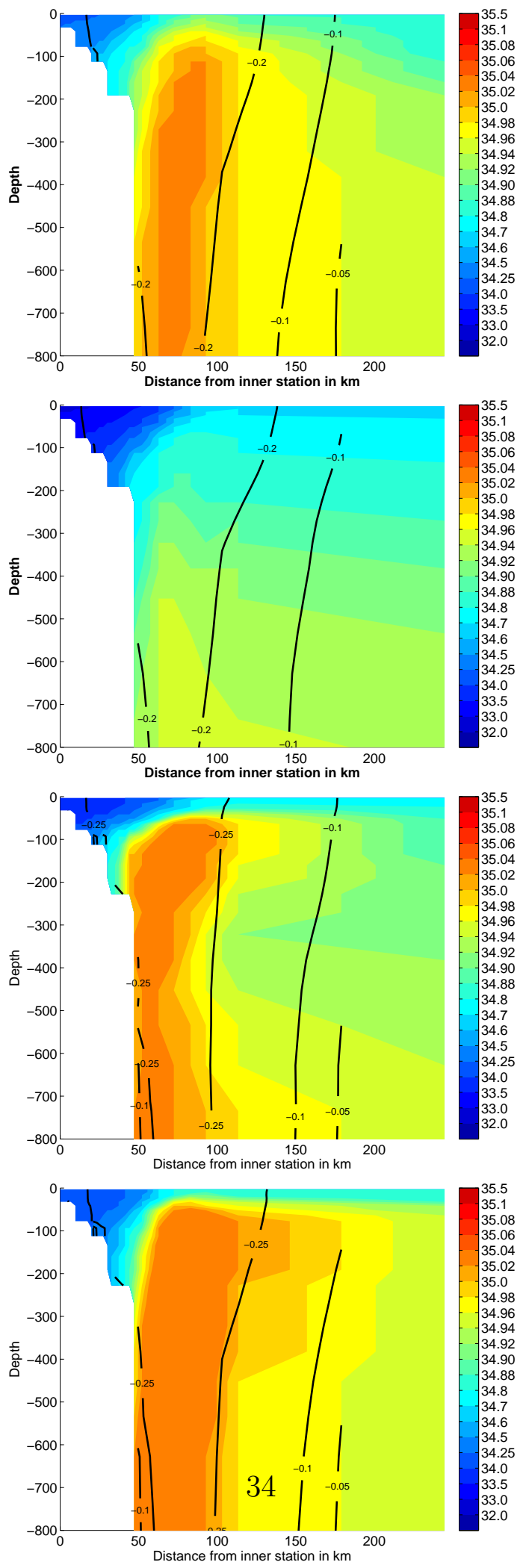

Figure 10: Model salinities and velocities projected onto section 1 of Sutherland and Pickart (2008) in the EGC to the east of Cape Farewell, for (a G70; (b) KAB001; (c) PVar and (d) PCon. For the two global simulations, the fields are based over the first 14 years of integration, while the fields from the regional North Atlantic simulations are based on the last year of integration. The solid lines are contours of model velocities perpendicular to the section. 

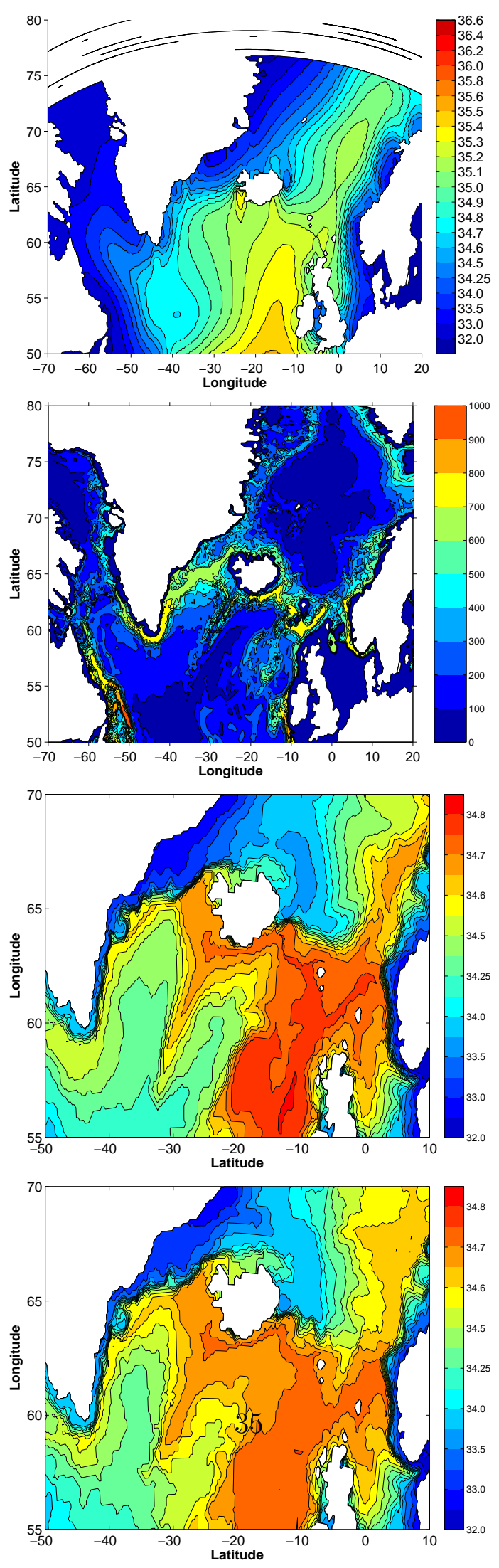

Figure 11: a) Annual mean of the sea surface salinity field used by the model simulations for surface relaxation; b) Annual mean of the eddy transfer coefficient, kappa, over the final year of integration from PVar in $m^{2} s^{-1}$; c) Monthly average upper layer salinity from December of year 14, from PVar; d) as c) but for PCon. 

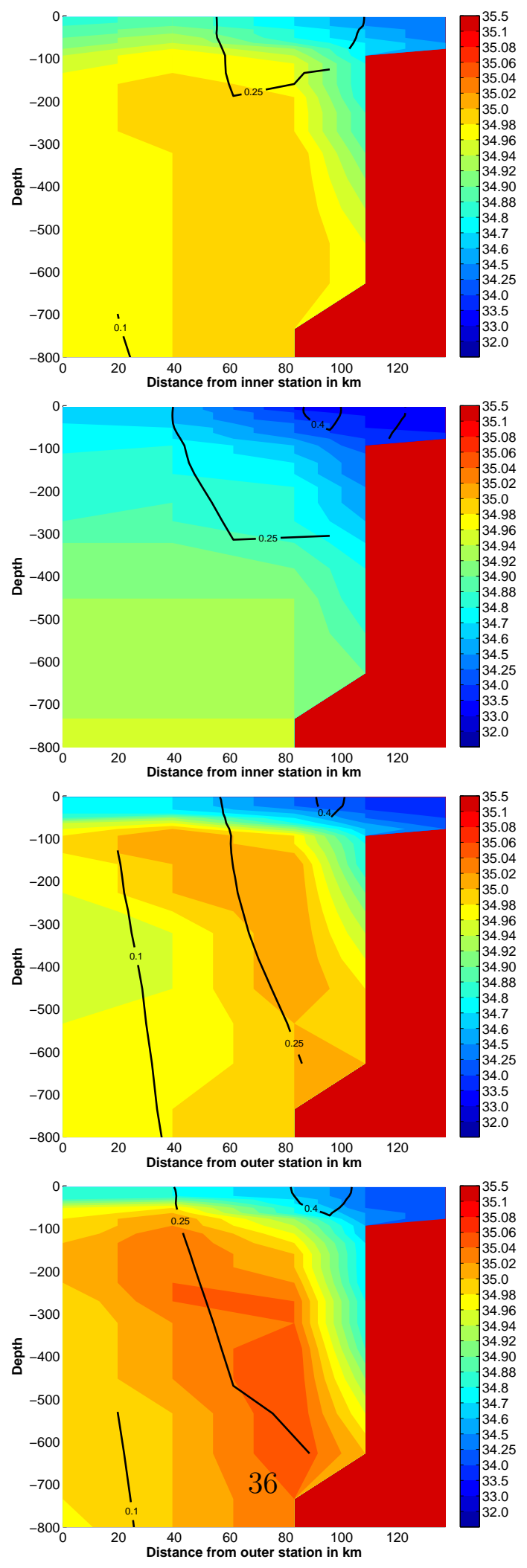

Figure 12: Model salinities and velocities projected onto a section across the WGC at Cape Farewell for (a) G70; (b) KAB001; (c) PVar and (d) PCon. For the two global simulations, the fields are based over the first 14 years of integration, while the fields from the regional North Atlantic simulations are based on the last year of integration. The solid lines are contours of model velocities perpendicular to the section. 